indicate the extent to which diabetic drivers may be a hazard on the roads. Clarke et al found that 33 of 86 male diabetic drivers experienced hypoglycaemic symptoms while driving, ${ }^{1}$ and J F Taylor of the Department of Transport (personal communication) has found that hypoglycaemia was responsible for $17 \%$ of 2000 cases in which a driver collapsed at the wheel while driving and became involved in a road traffic accident.

I am not impressed with Professor Sönksen's point that failure of intellectual function is a late manifestation of hypoglycaemia. Even if it is, the so called automatism of the hypoglycaemic state has been a major factor in several cases in which I have given evidence in court and has been responsible for the drivers yielding to a compulsion to continue driving when they were aware that it was irrational and dangerous to do so.

I would not dispute that most diabetics taking insulin are reasonably safe to drive but it does not seem illogical to draw a distinction between fitness to drive a private motor car and suitability for driving a public service vehicle or a heavy goods vehicle, particularly as $70 \%$ more deaths per mile are caused by heavy goods vehicles as opposed to motor cars (J Taylor, personal communication). Heavy goods vehicle and public service vehicle licences are granted by the traffic commissioners and in general they accept the advice of the Medical Commission on Accident Prevention that they should not be granted to diabetics taking insulin.

I do not believe that it is discriminatory to suggest that some occupations are unsuitable for diabetics taking insulin; it is sound medical advice.

JOHN LISTER

Windsor,

Berkshire SL4 3HH

' Clarke B, Ward JD, Enoch BA. Hypoglycaemia in insulin-depe

\section{Does metabolic bone disease follow truncal vagotomy and gastrojejunostomy?}

SIR, - The opening sentence of the article by Mr A D Irving and others (19 November, p 1516) states: "Up to $20 \%$ of patients who have undergone partial gastrectomy have been found to have metabolic bone disease 10 years later." This statement is in contradiction to the findings of a prolonged study of the results of gastrectomy in peptic ulcer that I carried out some years ago. ${ }^{2}$

A series of 998 patients underwent operation for peptic ulcer and were followed up continuously for periods of up to 20 years. ${ }^{1}$ Eight hundred patients had a modified type of Polya gastrectomy for duodenal ulcer and were subjected to special review with regard to malabsorption syndromes, including weight changes, postgastrectomy anaemia, and postgastrectomy bone disease. ${ }^{2}$ It was realised that the variables indicating bone disease were ill defined, but assessment was attempted on a combination of the clinical state, the radiological findings, the blood chemistry, and findings on bone biopsy. Biochemical screening of all cases included estimation of the serum calcium and serum phosphate concentrations, the calcium phosphate product, and the serum alkaline phosphatase activity. Radiological screening consisted of the estimation of the "metacarpal," "femoral," and "vertebral biconcavity" indices as described by Nordin, ${ }^{3}$ as well as the observation of osteoporotic changes in the spine, fractures of the ribs, or the presence of Loosers zones in the long bones.

After screening 13 subjects were selected for further scrutiny as possible cases of metabolic bone disease. In none of these cases could the diagnosis of postgastrectomy bone disease be confirmed, and other causes were found for the biochemical or radiological abnormality. In the three cases arousing the greatest suspicion of bone disease, bone biopsy showed no abnormality.

These results suggest that postgastrectomy bone disease is quite rare, that such radiological changes as were observed were the result of advancing age,$^{4}$ and that if a review of patients in the same age group were to be carried out a similar state of bone metabolism would be observed, as suggested by Slaney (personal communication). It comes as no surprise that the review of 59 patients carried out by $\mathrm{Mr}$ Irving and his colleagues showed no clinical evidence of osteoporosis or osteomalacia 11 years after vagotomy and gastrojejunostomy.

KenNeth McKeown

Darlington,

County Durham

McKeown KC. A study of peptic ulcer, with special reference to the results of partial gastrectomy. $\mathrm{Br} \mathcal{F}$ Surg 1962;220:131-49.

${ }^{2}$ McKeown KC. A prospective study of the immediate and long-term results of Polya gastrectomy for duodenal ulcer. Br 7 Surg 1972;59:849-68.

Nordin BEC. Metabolic bone and stone disease. 1973.

Newton-John HF, Morgan DB. Osteoporosis: disease or senescence. Lancet 1968; i:232-3.

\section{Rectal indomethacin for control of} postoperative pain

SIR,-We believe that Mr D St J Collier and Mr J A Pain (10 December, p 1799) are correct to draw attention to the disadvantages of indomethacin, particularly its effect on the gastrointestinal tract. We have been concerned about this since we first started using the drug in 1977 for the relief of postoperative pain.

In 1978 we studied 100 patients in a double blind trial comparing indomethacin with a placebo. The results showed that indomethacin was highly effective and considerably reduced the need for postoperative opiates. We did not publish our findings at this stage as one patient receiving indomethacin had a postoperative gastric haemorrhage; although the patient soon recovered we felt that caution was indicated. In view of the otherwise encouraging findings, however, we considered that further evaluation was justified. This we have continued to do, as has Mr Reasbeck, who was our registrar at the time of the original trial. Since 1978 about 1000 patients undergoing major thoracic surgery have received rectal indomethacin, and one of us (LI) has treated at least a further 3000 other surgical cases. None of these has developed signs of postoperative gastrointestinal bleeding. We do recommend that the dosage should not exceed $100 \mathrm{mg}$ every eight hours for a maximum of three days, though in many general surgical cases the drug can be stopped after 24 hours.

The rectal route was chosen as the oral route is unsatisfactory in the early postoperative period, particularly after major surgery. Rectal indomethacin is associated with fewer side effects in spite of its systemic action. ${ }^{1}$
Nowhere in our paper ( 5 November, p 1335) do we make the assumption that indomethacin replaces subcutaneous heparin in preventing deep vein thrombosis and pulmonary emboli. We do, however, advise against using both drugs together as there does appear to be a synergistic effect with an increased risk of postoperative bleeding.

From our six year experience we conclude that rectal indomethacin is an excellent postoperative analgesic. The ability of the patients to cough effectively and to cooperate with the physiotherapist is most striking. We consider that the benefits of the technique far outweigh the risks of serious peptic complications.

D J M KeENAN K CAVE

L LANGDON R E LEA

University Hospital of Wales,

Cardiff CF4 4XW

' Holt LJP, Hawkins CF. Indomethacin: studies of absorption and of the use of indomethacin sup-
positories. Br Med $\mathcal{F} 1965 ; \mathrm{i}: 1354-6$.

\section{Standards for reporting adverse drug reactions}

SIR,-Had the "minimal requirements" of Dr G C Berneker and others (3 December, p 1720) already been accepted in 1974 Professor Felix's letter to the editor on skin reactions to practolol $^{1}$ would have been rejected, as it does not comply with any of the postulates (except the name, but not the formulation of the drug). The consequences of a rejection need not be elaborated.

Medical journals like the $B M f$ are written, edited, and read by responsible and critical colleagues, who are, as a rule, able to separate wheat from chaff and need no muzzling.

KARL H KIMBEL

Arzneimittelkommission der
Deutschen Ärzteschaft,

5000 Köln 51,

West Germany

Felix R, Ive FA. Skin reactions to practolol. Br Med $\mathcal{J}$ 1974 ;ii: 333

\section{Intestinal perforation associated with} osmotic slow release indomethacin capsules

SIR,-Mr T K Day (3 December, p 1671) describes two patients who apparently suffered intestinal perforation at the time of ingestion of osmotic slow release indomethacin tablets. It is worth pointing out that the drug regimen for both patients should be considered unusual.

Case 1 was a 70 year old man who had been taking conventional indomethacin capsules $25 \mathrm{mg}$ three times daily. For some reason two weeks before admission his treatment was changed to the new preparation at double the dose (one tablet of Osmosin is equivalent to $25 \mathrm{mg}$ three times daily of the conventional capsule: he had been given one Osmosin tablet twice daily). The second patient had been maintained on benorylate, $4 \mathrm{~g}$ twice daily, for osteoarthritis and this had been "supplemented" by slow release indomethacin trihydrate $105 \mathrm{mg}$, again twice a day. The benorylate dosage was already at the upper part of the recommended range $(4 \mathrm{mg} / 10 \mathrm{ml}$ given $5-10 \mathrm{ml}$ twice daily). There is little evidence that the addition of a second nonsteroidal agent is beneficial, and certainly the 
risk of giving double the usual starting dose of a new agent in conjunction with the underlying benorylate should have been considered potentially dangerous.

That these patients were both in their 70 s should have invited particular care. Regardless of the attributes, or otherwise, of Osmosin or any new anti-inflammatory agent, it is unfortunate that a new drug should fall into disrepute as a result of inadequate attention to dosage, unwarranted polypharmacy, or lack of concern for the patient's age.

ANDRei Calin

Royal National Hospital for Rheumatic Diseases, Bath BA1 1RL

***The author replies below.-ED, BMf.

SIR,-I am grateful to Dr Calin for making this important point. My main object in reporting the two cases of intestinal ulceration in association with ingestion of Osmosin was to alert my colleagues in hospital practice to a possible new hazard, to point out that symptoms of intestinal perforation may be masked by non-steroidal anti-inflammatory drugs, and to suggest a rationale for treatment in any future cases. It was not my intention "to bring a new drug into disrepute."

With regard to the way that the drugs were prescribed the facts speak for themselves, and as a hospital clinician I would hesitate to criticise the family doctor on this point. After the report was accepted for publication Osmosin was withdrawn voluntarily by the manufacturers, to their great credit. This decision was probably right; Osmosin may possess intrinsic hazards irrespective of dosage. These hazards relate to the likelihood of a single capsule becoming lodged in a diverticulum or otherwise arrested, thereby directing a jet of indomethacin and potassium ions in high local concentration for several hours at one tiny area of intestinal mucosa.

\section{T K DAY}

Altnagelvin Hospital,

\section{Addiction to aerosol treatment}

SIR,-I should like to point out a potential problem for general practitioners treating young asthmatics who abuse salbutamol inhalers (19 November, p 1515; 17 December, p 1877), illustrated by a recent case in an adolescent patient.

A 17 year old boy whose asthma was not well controlled requested increasing numbers of repeat prescriptions for salbutamol inhalers, often several in the space of a few days. I decided to change his treatment from aerosols to inhalation capsules when he next attended the surgery. As the consultation progressed he became enraged and abusive and threatened to induce a severe attack of asthma unless he received a salbutamol inhaler. He would not accept the alternative of inhalation capsules and refused to leave the surgery. He was eventually given the desired prescriptions by another general practitioner. The viewpoint expressed by colleagues at the time was that there would be little danger from the overuse of salbutamol inhalers.

This case highlights the addictive nature of the problem, in contrast to the case histories published so far, which do not mention any difficulty in weaning such patients from salbutamol inhalers. As it is likely that the general practitioner will be the first to identify addiction to aerosol salbutamol, it is clearly important to be aware of potential difficulties in safely substituting alternative bronchodilator treatment. Enlisting psychiatric help, as suggested by $\mathrm{Dr}$ Thompson and others, could well be of value in such cases.

JUNe M RAINE

Donnington Health Centre, Oxford OX4 4DH

\section{Searching the literature}

SIR,-Dr W F Whimster (5 November, p 1322) refers to the Science Citation Index, a registered trademark of the Institute for Scientific Information. Although it is true that we index more than 600000 articles each year, our database contains (alas) only 90 million cited references not 900 million. We are adding about 10 million each year; of these about half are unique. Furthermore, though the most recent files are available on line, many years are not; indeed, we have just completed the 10 year cumulation covering the years 1955-64. So a more up to date figure for our files is now about 150000 citations.

I disagree with the assertion that all search systems retrieve too many publications. Nor is it necessarily time consuming to find those that are relevant to the particular needs of most papers.

Dr Whimster is, alas, wrong in his assumption that most authors use indexes like Science Citation Index to review previous work. I believe that Peter Morgan is correct in suggesting that literature searches should be described like any other method. ${ }^{1}$ Were this done regularly there would be fewer papers and even fewer with inadequate attention to prior claims. Once published, inadequately documented papers go on being cited even though subsequent disclaimers are published. The wide occurrence of this phenomenon led to the launch of the Science Citation Index in the first place.

\section{Eugene Garfield}

Institute for Scientific Information,

University City Science Center,

Philadelphia PA 19104,

USA

${ }^{1}$ Morgan PP. Covering and recovering the medical literature. Can Med Assoc f 1983;128:1264.

\section{Persecution of academics in Turkey}

SIR,-We wish to draw the attention of your readers to the persecution of academics by the Turkish government.

Professor Ozek of the department of psychiatry of the University of Istanbul was arbitrarily dismissed from his university position and, after spending eight months in prison before trial, was recently sentenced to eight years' imprisonment, while another member of his staff was recently dismissed from the university. Three years ago another member of the same department was imprisoned without trial for a month. The three staff concerned are talented psychiatric academics of great integrity, and there is absolutely no justification for such deplorable actions by the Turkish government.

This extreme attack on academic freedom and human rights by a fellow member of NATO, which is said to be defending the free world, should be strongly condemned. The greatest possible pressure should be exerted on the Turkish government to end such repressive measures.

ISAAC MARKS

Institute of Psychiatry,

London SE5 8AF

JOAN BICKNELI

K S BLUGLASS

MICHAEL BOND

SYDNEY BRANDON

R H CAWLEY

D ECCLESTON

GRIFFITH EDWARDS

J L GibBons

Philip J Graham

$S$ R HIRSCH

R E KENDELL

I Kolvin
W A LISHMAN
R H S MINDHAM
IAN OSWALD
E S PAYKeL
K RAWNSLEY
MARTIN ROTH
F H STONE
D TAYLOR
W H TRETHOWAN
A WaKeling
J P WATSON

\section{Inpatient waiting}

SIR,-Like Mr John G Cullis and Dr Philip R Jones (12 November, p 1483) we believe that existing waiting lists are "a problem that deserves resolution." Unlike these authors, however, we do not believe that the solution lies in the payment of selective subsidies to induce patients on waiting lists to seek private treatment.

Criticism of Mr Cullis's and Dr Jones's hypothetical example showing how such a scheme would prove a bargain to the Exchequer is best left to their fellow economists, but the disjunction between the example as it stands and the operation of waicing lists in the real world is far greater than they are prepared to acknowledge.

In the absence of adequate information about the various constituents of waiting lists and the process by which they are created and maintained, speculation about the role in regulating demand for NHS treatment will remain mere speculation and an unsound basis for formation of policies. A particular example of this is $\mathrm{Mr}$ Cullis's and Dr Jones's claim that any increased supply of NHS services will result in a proportionate increase in demand expressed as a readjustment of the waiting list to its original level. Furthermore, they suggest that this is due to doctors' response to the newly created capacity and unlimited pool of unmet demand for treatment.

This suggested relation between supply and demand within the NHS is used by Mr Cullis and Dr Jones as an argument against the expansion of NHS services. It is also implicit in a central, and otherwise unexplained, claim which they make concerning the value of subsidies: the take up of subsidies is assumed to create new demand for treatment strictly in line with an increased capacity in the private sector. Only if demand can confidently be predicted to follow this pattern can Mr Cullis and Dr Jones claim that NHS waiting lists will remain at the reduced level brought about by the initial subsidies. This must be doubtful. The jump from believing that people will be willing to "pay a little extra" to supposing that a $6 \%$ subsidy would entice them to pay the remaining costs is hard to follow. Although the figures are hypothetical, the order of magnitude by which they would have to be changed to become credible would destroy the basis of the calculation.

If this extra demand for treatment in the private sector was not forthcoming, the scheme would function solely to subsidise the speed of treatmen of those who could afford it at the expense of those who could not. Income related subsidies 